\title{
Estimation of Oxidation Kinetics and Oxide Scale Void Position of Ferritic-Martensitic Steels in Supercritical Water
}

\author{
Li Sun and Weiping Yan \\ School of Energy Power and Mechanical Engineering, North China Electric Power University, Yong Hua Bei No. 619, \\ Lian Chi District, Baoding 071003, China \\ Correspondence should be addressed to Li Sun; sunli1001315@163.com
}

Received 28 March 2017; Revised 13 June 2017; Accepted 20 July 2017; Published 30 August 2017

Academic Editor: Pavel Lejcek

Copyright (C) 2017 Li Sun and Weiping Yan. This is an open access article distributed under the Creative Commons Attribution License, which permits unrestricted use, distribution, and reproduction in any medium, provided the original work is properly cited.

\begin{abstract}
Exfoliation of oxide scales from high-temperature heating surfaces of power boilers threatened the safety of supercritical power generating units. According to available space model, the oxidation kinetics of two ferritic-martensitic steels are developed to predict in supercritical water at $400^{\circ} \mathrm{C}, 500^{\circ} \mathrm{C}$, and $600^{\circ} \mathrm{C}$. The iron diffusion coefficients in magnetite and $\mathrm{Fe}-\mathrm{Cr}$ spinel are extrapolated from studies of Backhaus and Töpfer. According to Fe-Cr-O ternary phase diagram, oxygen partial pressure at the steel/Fe-Cr spinel oxide interface is determined. The oxygen partial pressure at the magnetite/supercritical water interface meets the equivalent oxygen partial pressure when system equilibrium has been attained. The relative error between calculated values and experimental values is analyzed and the reasons of error are suggested. The research results show that the results of simulation at $600^{\circ} \mathrm{C}$ are approximately close to experimental results. The iron diffusion coefficient is discontinuous in the duplex scale of two ferritic-martensitic steels. The simulation results of thicknesses of the oxide scale on tubes (T91) of final superheater of a $600 \mathrm{MW}$ supercritical boiler are compared with field measurement data and calculation results by Adrian's method. The calculated void positions of oxide scales are in good agreement with a cross-sectional SEM image of the oxide layers.
\end{abstract}

\section{Introduction}

According to the characteristic of supercritical water [1], supercritical and ultrasupercritical boiler power plants have been constructed for a long time in order to improve efficiency of units in some countries. Under the supercritical water (the critical point of water, $374^{\circ} \mathrm{C}, 22.1 \mathrm{MPa}$ ) environment, the corrosion resistance of candidate materials is one of the key requirements for these materials safe application in units. Two ferritic-martensitic steels of candidate structural materials for superheaters and reheaters, such as HCM12A and NF616, have been attracted increasing attention by researchers, because they have good hightemperature strength, high thermal conductivity, creep resistance, and low thermal expansion coefficients [2]. Exfoliation of oxide scales from high-temperature heating surfaces of power boilers threatened the safety of supercritical power generating units, and prediction of oxidation kinetics and void formation of oxide scales are desired.
Generally, good corrosion resistance of the steels with higher $\mathrm{Cr}$ contents is presented compared to the steels with lower $\mathrm{Cr}$ contents $[3,4]$. In order to understand the oxidation mechanism of candidate materials under supercritical water environment, the oxidation tests of ferritic-martensitic steels are performed and the effects of SCW temperature and dissolved oxygen on the oxidation rate are analyzed. The diffusion processes in oxide in terms of diffusion species and mechanisms are determined and the structure of the various oxide phases and their formation are understood [5]. In situ electrical and electrochemical measurements during oxidation of ferritic steel P91 and austenitic steel AISI 316L (NG) in ultrasupercritical water $\left(500-700^{\circ} \mathrm{C}, 30 \mathrm{MPa}\right)$ have been carried out. The surface and in-depth composition and structure of the oxides formed on ferritic and austenitic steels in ultrasupercritical water are broadly analogous to those obtained by wet air oxidation in the same temperature range [6]. Angell et al. [7] studied the effect of pressure on the steam oxidation of $9 \mathrm{Cr}-1 \mathrm{Mo}$ steels at $500-600^{\circ} \mathrm{C}$ and the 
oxidation of the steels followed a parabolic kinetics with the oxide scale thickness increasing with the increasing pressure. The corrosion of the ferritic-martensitic steel P92 exposed to supercritical water at $550^{\circ} \mathrm{C}$ under $25 \mathrm{MPa}$ with the dissolved oxygen contents of 100,300, and 2000 ppb was investigated. The results indicated that the weight gain increased with the dissolved oxygen content [8]. The oxidation behavior of ferritic/martensitic steel HCM12A exposed in SCW at $500^{\circ} \mathrm{C}, 25 \mathrm{MPa}$, and two levels of oxygen partial pressure were investigated. Oxygen partial pressure effects on oxide structure and porosity in oxide scale are rationalized in terms of thermodynamics and diffusion mechanism. A desirable continuous protective oxide layer structure with limited pores may be obtained by controlling the oxygen partial pressure [9]. Various growth mechanisms of the oxide scale of $9-12 \%$ Cr F-M steels exposed to SCW were proposed by Ampornrat and Was [5], Bischoff and Motta [10], and Zhong et al. [11]. The oxide films on F-M steels followed parabolic oxidation kinetics under supercritical water. Microstructure of oxide formed on four F-M steels consisting of two oxide layers and a transition layer. The outer oxide consisted of dense columnar grains of magnetite $\left(\mathrm{Fe}_{3} \mathrm{O}_{4}\right)$. The inner oxide consisted of small equiaxed grains of Fe-Cr spinel oxide $\mathrm{Fe}_{3-x} \mathrm{Cr}_{x} \mathrm{O}_{4}$, where $x(0.7-1)$ depends on alloy type. The transition layer consisted of grain boundary oxides of chromia and chromite and fine oxide grains of a spinel structure precipitated inside laths [5]. Martinelli et al. [12] focused on the growth kinetics simulation of a duplex oxide scale of a Fe-9Cr-1Mo martensitic steel (T91) in static liquid $\mathrm{Pb}-\mathrm{Bi}$. The magnetite layer growth is controlled by iron diffusion inside the $\mathrm{Fe}-\mathrm{Cr}$ spinel and the magnetite lattice. An analytical simulation is matched with the experimental kinetics. Rouillard and Martinelli [13] have suggested that $9 \mathrm{Cr}-1 \mathrm{Mo}$ steel forms in $\mathrm{CO}_{2}$ at $550^{\circ} \mathrm{C} \mathrm{a}$ duplex oxide layer containing an outer magnetite scale and an inner Fe-Cr rich spinel scale. The inner spinel oxide layer is formed according to a void-induced oxidation mechanism. The kinetics of the total oxide growth are simulated from the proposed oxidation model.

To sum up, the research of oxidation kinetics of two ferritic-martensitic steels is focused on experiments; simulation about oxidation kinetics is relatively few. In the present study, the growth kinetics of oxide films of ferritic-martensitic steel under supercritical water are simulated. Considering the presence of Fe-Cr rich spinel oxide layer, the oxidation rates of magnetite layer and $\mathrm{Fe}-\mathrm{Cr}$ rich spinel oxide layer are calculated simultaneously. With thermodynamic analysis of reaction of materials and calculation of oxygen activity at the interface, the growth kinetics of the inner layer and the outer layer are simulated. The results of simulation of oxidation of two ferritic-martensitic steels under supercritical water are compared to the experimental data in Tan et al. [14]. An example of one power plant is given. The calculated thickness and quantitative location of voids formation of oxide scale are compared with the experimental results.

\section{Assumptions and Formulas of Simulation}

Oxidation of different $\mathrm{Fe}-\mathrm{Cr}$ steels under steam, $\mathrm{CO}_{2}$, and $\mathrm{LBE}$ leads to the formation of a duplex oxide scale, and the characteristic of oxide scales is similar. Microstructure of oxide formed on the two steels consisted of two oxide layers, which are a Fe-Cr spinel oxide and a magnetite layer. The oxide thickness ratio is close to 1 , and the oxidation rate constant of the two layers follows approximately the parabolic law. The "available space model" is proposed to explain the oxidation mechanism of the duplex oxide scale [15]. In the "available space" model, the thickness ratio between the oxide layers formed is constant with exposure time, because the growth mechanism of both oxide layers is linked. Furthermore, the kinetics of oxidation and especially the growth of the inner layer are not limited by the diffusion of oxygen, which reaches the oxide-metal interface through short-circuits such as microchannels. In general, the original oxide-metal interface corresponds to the outer-inner layer interface during the oxidation of alloys under supercritical water. The outer layer is formed by outward migration of iron while the inner layer is formed by inwards migration of the oxidant. Consequently, the limiting step in this mechanism is the diffusion of iron, which enables the formation of the available space for the oxide to grow in. So the growth of oxide scales is dependant on the diffusion of iron in the double layers.

In order to simulate the oxide growth on ferriticmartensitic steels surface during exposure to supercritical water, the following assumptions are made:

(1) The oxide scale formed on ferritic-martensitic steels in supercritical water contains a dual structure. The outer layer, in contact with supercritical water, is a magnetite layer which grows at the magnetite/supercritical water interface involving an iron diffusion from the steel to this external interface. The inner layer, in contact with the steel, consisted of $\mathrm{Fe}-\mathrm{Cr}$ spinel layer involving a transport of oxygen from supercritical water to the steel/oxide interface. The iron flux across the $\mathrm{Fe}-\mathrm{Cr}$ spinel is equal to the iron flux across the magnetite layer. A steady state is reached at the interface between the two oxide layers.

(2) Thermodynamic equilibrium exists at both the steel/oxide and oxide/supercritical water interfaces.

(3) The composition concentrations are constant at the interfaces.

(4) The growth of oxide scales follows parabolic laws.

(5) The oxygen activity is constant at interfaces.

(6) The Fe-Cr spinel oxide slightly deviates from the stoichiometry.

(7) The oxide scale is compact and adherent and voids and cracks in the oxide may be neglected.

(8) The dissociation of oxide scales is neglected

Generally, the thickness of consumption of ferriticmartensitic steel is equal to the thickness of the Fe-Cr spinel layer. The relation between the thickness of $\mathrm{Fe}-\mathrm{Cr}$ spinel layer 
and that of the magnetite layer can be described as follows [12]:

$$
h_{\text {spinel }}=\frac{C_{\mathrm{Fe}(\text { magnetite })}}{C_{\mathrm{Fe}(\text { steel })}-C_{\mathrm{Fe}(\text { spinel })}} h_{\text {magnetite }}
$$

where $h_{\text {spinel }}$ and $h_{\text {magnetite }}$ are the thicknesses of the Fe$\mathrm{Cr}$ spinel layer and the magnetite layer $(\mu \mathrm{m}) . C_{\mathrm{Fe} \text { (magnetite) }}$, $C_{\mathrm{Fe}(\text { spinel) }}$, and $C_{\mathrm{Fe}(\text { steel) }}$ are the concentrations of $\mathrm{Fe}$ in magnetite, spinel oxide, and steel substrate $\left(\mathrm{mol} / \mathrm{cm}^{3}\right)$, respectively.

For a given time, the formula of the thickness of oxide scale is as follows:

$$
h^{2}=k_{p} t
$$

where $h$ is the thickness of the entire oxide or the thickness of the spinel layer or the thickness of the magnetite layer and $k_{p}$ is the oxidation rate constant $\left(\mathrm{cm}^{2} / \mathrm{s}\right)$, respectively. $t$ is time (s).

According to Wagner's theory of oxidation and considering that magnetite is formed by outward migration of Fe ions, the oxidation rate constant of oxide obeys the law as proposed by Atkinson et al. [16]:

$$
k_{p}=\frac{4}{3} \int_{a_{\mathrm{O}_{2}}^{\prime}}^{a_{\mathrm{O}_{2}}^{\prime \prime}} f^{-1} D^{*} d \ln a_{\mathrm{O}_{2}},
$$

where $a_{\mathrm{O}_{2}}^{\prime}$ and $a_{\mathrm{O}_{2}}^{\prime \prime}$ are the oxygen activities at oxide/environment interface and steel/oxide interface and $f$ is the correlation factor for the diffusion mechanism and is approximately equal to $0.5 . D^{*}$ is the tracer diffusion coefficient of $\mathrm{Fe}$ in oxide. $a_{\mathrm{O}_{2}}^{\prime}=P_{\mathrm{O}_{2}}^{\prime} / P_{\mathrm{O}_{2}}^{0}, P_{\mathrm{O}_{2}}^{\prime}$ is the oxygen partial pressure (atm) at the interface, $P_{\mathrm{O}_{2}}^{0}=1$ atm.

The diffusion coefficient of $\mathrm{Fe}$ in oxide is very dependent on different types of defects that are present in the oxide lattice. The concentration of defects is linked to the oxygen activity in oxide scales and the diffusion coefficient of Fe ions is dependent on the oxygen activity in two oxide layers. The diffusion coefficient of Fe ions in magnetite can be expressed by oxygen activity and temperature, and the equation can be written [17]:

$$
D_{\mathrm{Fe}, \mathrm{mag}}=\frac{A a_{\mathrm{O}_{2}}^{2 / 3}}{\left(1+2 K_{V} a_{\mathrm{O}_{2}}^{2 / 3}\right)}+B a_{\mathrm{O}_{2}}^{-2 / 3}
$$

where $A=D_{V} K_{V} / 12, B=4 D_{I} K_{I} / 3, D_{V}$ and $D_{I}$ are self-diffusion coefficients of cation vacancies and iron interstitials, and $K_{V}$ and $K_{I}$ are the equilibrium constants for the formation of cation vacancies and iron interstitials in magnetite. The first term and the second term as a function of temperature and oxygen activity represent the iron diffusion via vacancies and interstitials. The diffusion of Fe in the outer oxide layer at high-oxygen activities is governed by cation vacancies and cation interstitials at low-oxygen activities.
The diffusion coefficient of Fe in Fe-Cr spinel oxide layer can be expressed by the following relation [13]:

$$
\begin{aligned}
D_{\mathrm{Fe}, \text { spinel }} & =R_{V} \frac{A a_{\mathrm{O}_{2}}^{2 / 3}}{\left(1+2 K_{V} a_{\mathrm{O}_{2}}^{2 / 3}\right)}+R_{I} B a_{\mathrm{O}_{2}}^{-2 / 3} \\
R_{V} & =\frac{D_{\text {spinel, } V}^{\text {topfer }}}{D_{\text {mag, } V}^{\text {topfer }}} \\
R_{I} & =\frac{D_{\text {spinel }, I}^{\text {topfer }}}{D_{\text {mag }, I}^{\text {topfer }}}
\end{aligned}
$$

where $D_{\text {mag, } V}^{\text {topfer }}$ and $D_{\text {mag, } I}^{\text {topfer }}$ are the partial cation diffusion coefficients of the cation diffusion via vacancies $(V)$ and interstitials $(I)$ in $\mathrm{Fe}_{3} \mathrm{O}_{4} . D_{\text {spinel, } V}^{\text {topfer }}$ and $D_{\text {spinel, } I}^{\text {topfer }}$ are the partial cation diffusion coefficients of the cation diffusion via vacancies $(V)$ and interstitials $(I)$ in Fe-Cr spinel oxide layer. $R_{V}$ and $R_{I}$ are the ratios of $D_{V}$ and $D_{I}$ of $\mathrm{Fe}-\mathrm{Cr}$ spinel oxide to that of $\mathrm{Fe}_{3} \mathrm{O}_{4}$ by Töpfer et al's data [18].

According to assumption (1), the iron flux across the Fe$\mathrm{Cr}$ spinel is equal to the iron flux across the magnetite layer. The oxygen activity at the interface of ferritic-martensitic steel/Fe-Cr spinel layer is determined from the oxygen partial pressure of the phase boundary at different temperatures. The oxygen activity at the interface of magnetite/supercritical water is calculated by the thermodynamics equilibrium between $\mathrm{Fe}_{3} \mathrm{O}_{4}$ and $\mathrm{Fe}_{2} \mathrm{O}_{3}$. The oxygen activity at the interface of magnetite/Fe-Cr spinel is unknown. According to (1)-(5), the oxidation rates and thickness of magnetite layer and $\mathrm{Fe}-\mathrm{Cr}$ spinel layer and the oxygen activity at the interface of magnetite/Fe-Cr spinel can be evaluated.

\section{Determination of the Parameters}

Two types of ferritic-martensitic steels HCM12A and NF616 were evaluated in this study. The oxidation rates of these steels are calculated in supercritical water at $400^{\circ} \mathrm{C}, 500^{\circ} \mathrm{C}$, and $600^{\circ} \mathrm{C}$ under $25 \mathrm{MPa}$. A summary of steel composition in weight percent is presented in Table 1 [14].

The densities of F-M steels and magnetite are $7.77 \mathrm{mg} / \mathrm{cm}^{3}$ and $5.17 \mathrm{mg} / \mathrm{cm}^{3}$, respectively. The mole volume of $\mathrm{Fe}-$ Cr spinel oxide approximately equals that of magnetite because the lattice parameter of Fe-Cr spinel oxide is close to that of magnetite. According to chemical compositions of the ferritic-martensitic steels HCM12A and NF616 and the densities of scales, the concentrations of $\mathrm{Fe}$ in magnetite, spinel oxide, and steel substrate, $C_{\mathrm{Fe} \text { (magnetite) }}, C_{\mathrm{Fe}(\text { steel) }}$,

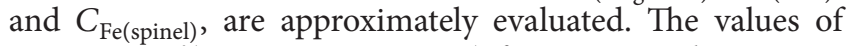
$C_{\mathrm{Fe} \text { (magnetite) }} /\left(C_{\mathrm{Fe} \text { (steel) }}-C_{\mathrm{Fe} \text { (spinel) }}\right)$ for NF616 and HCM12A are 0.985 and 0.932 , respectively.

3.1. Determination of Iron Diffusion Coefficient in Magnetite and $\mathrm{Fe}-\mathrm{Cr}$ Spinel Oxide. The iron diffusion coefficient in magnetite at lower temperatures can be extrapolated from the data of the iron diffusion coefficient for temperatures between 900 and $1400^{\circ} \mathrm{C}$, which is given by Backhaus-Ricoult and 
TABLE 1: Chemical composition of HCM12A and NF616 (in wt\%).

\begin{tabular}{|c|c|c|c|c|c|c|c|c|c|c|c|c|c|c|}
\hline Steel & $\mathrm{C}$ & $\mathrm{Mn}$ & $\mathrm{P}$ & S & $\mathrm{Si}$ & $\mathrm{Ni}$ & $\mathrm{Cr}$ & Mo & $\mathrm{Cu}$ & $\mathrm{N}$ & $\mathrm{Nb}$ & $\mathrm{Al}$ & V & W \\
\hline HCM12A & 0.11 & 0.64 & 0.016 & 0.002 & 0.27 & 0.39 & 10.83 & 0.3 & 1.02 & 0.063 & 0.054 & 0.001 & 0.19 & 1.89 \\
\hline NF616 & 0.109 & 0.45 & & & 0.102 & 0.174 & 8.82 & 0.468 & & & 0.064 & & 0.194 & 1.87 \\
\hline
\end{tabular}

Dieckmann [17]. For the iron diffusion coefficient in spinel oxide, the data at $1200^{\circ} \mathrm{C}$ given by Töfpfer et al. [18] is used and extrapolated towards lower temperature. Assuming the same temperature dependence for iron diffusion in magnetite and in $\mathrm{Fe}-\mathrm{Cr}$ spinel, the ratio between iron diffusion coefficient in magnetite and in spinel oxide is a function of oxygen activity.

The mean values of the ratio between iron diffusion coefficient via vacancies or interstitials in spinel oxide and in magnetite for different experimental points at $1200^{\circ} \mathrm{C}$ are calculated, namely, $R_{V}$ and $R_{I}$. For NF616, composition of inner oxide scale is $\mathrm{Fe}_{2.4} \mathrm{Cr}_{0.6} \mathrm{O}_{4}$ [19], $R_{V}$ equals 0.644 , and $R_{I}$ equals 0.31 . For HCM12A, composition of inner oxide scale is $\mathrm{Fe}_{2} \mathrm{CrO}_{4}[19], R_{V}$ equals 0.5 , and $R_{I}$ equals 0.039 .

\subsection{Estimation of the Oxygen Activities of Magnetite/Super-} critical Water Interface and Steel Substrate/Fe-Cr Spinel Interface. Formation of oxide phase depends on the oxygen potential and local chemistry, which can be described by the diffusion path in Fe-Cr-O phase diagrams [19]. The oxygen partial pressure at this interface could be determined from the phase boundary in the predominance diagram. The oxygen partial pressures at steel substrate/Fe-Cr spinel interface are approximately $3 \times 10^{-35}$ atm, $1 \times 10^{-29}$ atm, and $2 \times 10^{-25}$ atm for $400^{\circ} \mathrm{C}, 500^{\circ} \mathrm{C}$, and $600^{\circ} \mathrm{C}$, respectively.

The real oxygen concentration at the magnetite/atmosphere interface is not the oxygen concentration in air or water. Zurek et al. [20], who studied oxidation of $10 \% \mathrm{Cr}$ ferritic steel in $\mathrm{Ar}-\mathrm{H}_{2} \mathrm{O}$ mixture, showed that the oxide scale thickness does not depend on the $\mathrm{H}_{2} \mathrm{O}$ content in the gas mixture $\left(\mathrm{Ar}-4 \% \mathrm{H}_{2} \mathrm{O}\right.$ or $\left.\mathrm{Ar}-50 \% \mathrm{H}_{2} \mathrm{O}\right)$ if the oxygen activity is sufficient to allow the thin hematite layer formation. The estimated oxygen partial pressure using Henry's constant of SCW is lower than that of steam. The values also are still quite high compared to a dissociation $P_{\mathrm{O}_{2}}$ of surface oxide phase (magnetite) observed. It can be assumed that the dissolved oxygen was totally removed from water under deaerated condition, and oxygen was miscible under SCW. Therefore, the oxygen partial pressure at specimen surface was very low and resulted from dissociation of water molecules only [19]. The oxidation rate of oxide scale is related to oxygen activity at magnetite/supercritical water. Furukawa et al. [21] suggested that the oxide growth kinetics do not depend on the nature of the oxidizing medium but just on the oxygen activity in the oxidizing medium.

Fe transports through the spinel oxide layer and reacts with $\mathrm{H}_{2} \mathrm{O}$; the $\mathrm{Fe}_{3} \mathrm{O}_{4}$ layer becomes thick gradually as exposure time increases. At magnetite/supercritical water interface, $\mathrm{Fe}_{2} \mathrm{O}_{3}$ is formed through reaction (6) at the grain boundary of magnetite. With outward transport of $\mathrm{Fe}$ and inward transport of oxidation species along the oxide grain boundaries and short-circuit paths, both the $\mathrm{Fe}_{3} \mathrm{O}_{4}$ layer
TABLE 2: Thermodynamic data of oxidation reaction (6) at different temperatures.

\begin{tabular}{lccc}
\hline $\begin{array}{l}\text { Temperature } \\
\left({ }^{\circ} \mathrm{C}\right)\end{array}$ & $\Delta G_{T}(\mathrm{~J})$ & $P_{\mathrm{H}_{2} \mathrm{O}} / P_{\mathrm{H}_{2}}$ ratio & $\begin{array}{c}\text { Equivalent oxygen } \\
\text { partial pressure } \\
P_{\mathrm{O}_{2}}(\text { atm })\end{array}$ \\
\hline 400 & 51544 & 10016 & $3.46 \times 10^{-25}$ \\
500 & 59714 & 10846 & $3.5 \times 10^{-20}$ \\
600 & 67884 & 11532 & $2.57 \times 10^{-16}$ \\
\hline
\end{tabular}

and $\mathrm{Fe}-\mathrm{Cr}$ spinel layer became thicker. The real oxygen partial pressure at magnetite/supercritical water interface is not dissolved oxygen partial pressure, but the equivalent oxygen pressure which corresponds to the thermodynamic equilibrium of the following.

$$
2 \mathrm{Fe}_{3} \mathrm{O}_{4}+\mathrm{H}_{2} \mathrm{O} \longrightarrow 3 \mathrm{Fe}_{2} \mathrm{O}_{3}+\mathrm{H}_{2}
$$

Using Gaskell's data [22], the standard free energy for the formation of reaction (6) is given by

$$
\Delta G_{T}=-3440+81.7 T \text {. }
$$

At $600^{\circ} \mathrm{C}, \Delta G_{T}=67884 \mathrm{~J}$, and the equilibrium $P_{\mathrm{H}_{2} \mathrm{O}} / P_{\mathrm{H}_{2}}$ ratio is 11532. According to dissociation equation, Gibbs free energy, and water dissociation reaction rate, the equivalent oxygen pressure at magnetite/supercritical water interface can be evaluated. The equivalent oxygen partial pressure magnetite/supercritical water interface is as follows at $400^{\circ} \mathrm{C}$, $500^{\circ} \mathrm{C}$, and $600^{\circ} \mathrm{C}$ in Table 2.

3.3. Relation between Weight Gain and Thickness of Inner and Outer Layers of Oxide Scale. The weight gain of oxide scales is related to oxide thickness as a linear function because of oxygen absorption during exposure. The density of oxide scales is nearly constant, and the thickness of inner and outer layers of oxide scales is becoming thicker with exposure time increasing. The relation between weight gain and thickness of inner and outer layers of oxide scale was estimated by the following equation [8]:

$$
\begin{aligned}
\Delta w= & \rho_{\text {outer }} h_{\text {outer }}\left(\frac{4 M_{o}}{M_{\mathrm{Fe}_{3} \mathrm{O}_{4}}}\right) \\
& +\rho_{\text {inner }} h_{\text {inner }}\left(\frac{4 M_{o}}{M_{\mathrm{Fe}_{3} \mathrm{O}_{4}-\mathrm{FeCr}_{2} \mathrm{O}_{4}}}\right),
\end{aligned}
$$

where $\Delta w$ is the amount of absorbed oxygen per unit area in $\mathrm{mg} / \mathrm{cm}^{2}, \rho_{\text {outer }}$ and $\rho_{\text {inner }}$ are the outer and inner layer density $\left(\mathrm{mg} / \mathrm{cm}^{3}\right)$, respectively, $h_{\text {outer }}$ and $h_{\text {inner }}$ are the outer and inner layer thickness $(\mathrm{cm})$, respectively, $4 M_{o}$ are the mole mass of oxygen in oxide layer, and $\mathrm{M}_{\mathrm{Fe}_{3} \mathrm{O}_{4}}$ and $\mathrm{M}_{\mathrm{Fe}_{3} \mathrm{O}_{4}-\mathrm{FeCr}_{2} \mathrm{O}_{4}}$ are the mole mass of outer and inner layer, respectively. 


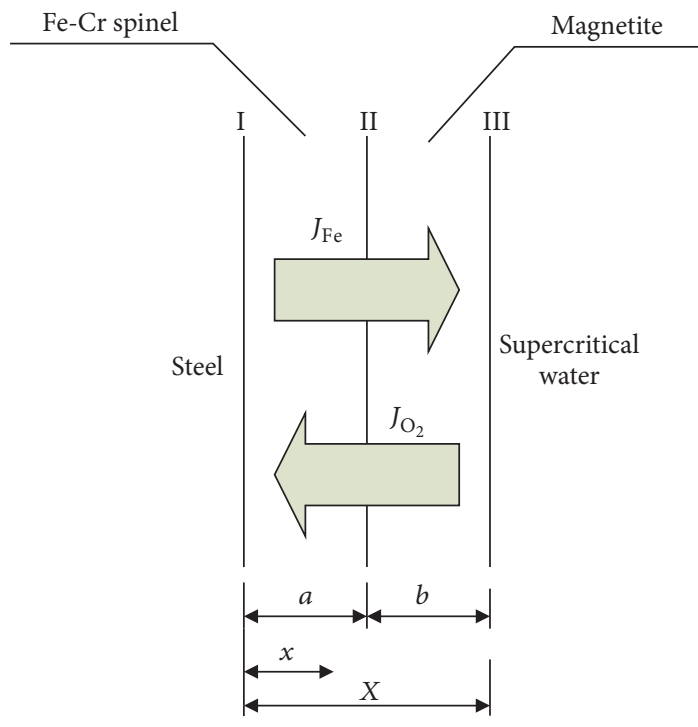

Figure 1: Schematic illustration of diffusion of oxygen and iron in the duplex scale in the magnetite and $\mathrm{Fe}-\mathrm{Cr}$ spinel formation process.

3.4. The Description of the Oxygen Activity, Iron Diffusion Coefficient, the Flux of Oxide Ion, and Its Divergence in Oxide as a Function of the Location $(x / X)$ in the Duplex Scale. Figure 1 shows a schematic illustration of diffusion of oxygen and iron in the duplex scale formed on ferritic-martensitic steel. The iron migrates outward during the growth of the duplex scale, while the oxidant migrates inwards.

The flux of iron in the Fe-Cr spinel layer formed on NF616 is described as [23]

$$
J_{\mathrm{Fe}}=\frac{2 C_{\mathrm{Fe}(\text { spinel })} D_{\mathrm{Fe}, \text { spinel }}}{2.4} \frac{d \ln a_{\mathrm{O}_{2}}}{d x} .
$$

The integration is performed over the entire $\mathrm{Fe}-\mathrm{Cr}$ spinel layer.

$$
J_{\mathrm{Fe}} a=\frac{2 C_{\mathrm{Fe}(\text { spinel })}}{2.4} \int_{a_{\mathrm{O}_{2}}(\mathrm{I})}^{a_{\mathrm{O}_{2}}(\mathrm{II})} D_{\mathrm{Fe}, \text { spinel }} d \ln a_{\mathrm{O}_{2}} .
$$

Equation (9) is integrated from $x=0$ to $x=x$ :

$$
J_{\mathrm{Fe}} x=\frac{2 C_{\mathrm{Fe}(\text { spinel })}}{2.4} \int_{a_{\mathrm{O}_{2}}(\mathrm{I})}^{a_{\mathrm{O}_{2}}} D_{\mathrm{Fe}, \text { spinel }} d \ln a_{\mathrm{O}_{2}} .
$$

The values of $a, b$, and $X$ are the thickness of $\mathrm{Fe}-\mathrm{Cr}$ spinel layer, magnetite layer, and entire duplex scale layer, respectively; that is, $a+b=X$. The relationship between the oxygen activity and the location $(x / X)$ in the Fe-Cr spinel layer can be derived as follows:

$$
\frac{x}{X}=\frac{\int_{a_{\mathrm{O}_{2}}(\mathrm{I})}^{a_{\mathrm{O}_{2}}} D_{\mathrm{Fe}, \text { spinel }} d \ln a_{\mathrm{O}_{2}}}{\int_{a_{\mathrm{O}_{2}}(\mathrm{I})}^{a_{\mathrm{O}_{2}}(\mathrm{II})} D_{\mathrm{Fe}, \text { spinel }} d \ln a_{\mathrm{O}_{2}}} \frac{a}{a+b} \quad 0 \leq x \leq a .
$$

According to assumption (1), the iron flux across the Fe$\mathrm{Cr}$ spinel is equal to the iron flux across the magnetite layer.
With the above method, the relationship between the oxygen activity and the location $(x / X)$ in the magnetite layer can be expressed as

$$
\begin{aligned}
& \frac{x}{X}=\frac{\int_{a_{\mathrm{O}_{2}}(\mathrm{II})}^{a_{\mathrm{O}_{2}}} D_{\mathrm{Fe}, \mathrm{mag}} d \ln a_{\mathrm{O}_{2}}}{\int_{a_{\mathrm{O}_{2}}(\mathrm{II})}^{a_{\mathrm{O}_{2}}(\mathrm{III})} D_{\mathrm{Fe}, \mathrm{mag}} d \ln a_{\mathrm{O}_{2}}} \frac{b}{a+b}+\frac{a}{a+b} \\
& a \leq x \leq b .
\end{aligned}
$$

3.5. Process of the Calculation. The oxygen partial pressure at the magnetite/SCW interface could be determined from FeCr-O phase diagrams [19]. The oxygen partial pressure at the steel/Fe-Cr spinel interface can be calculated by the thermodynamical equilibrium of reaction (6) from Section 3.2.

The oxygen activities (i.e., $a_{\mathrm{O}_{2}}$ (I) and $a_{\mathrm{O}_{2}}$ (III)) at the magnetite/SCW and the steel/Fe-Cr spinel interfaces are known. The only unknown variable is thus the oxygen activity $\left(a_{\mathrm{O}_{2}}(\mathrm{II})\right)$ at the $\mathrm{Fe}-\mathrm{Cr}$ spinel/magnetite interface. With (1)-(5), the oxygen activity $\left(a_{\mathrm{O}_{2}}(\mathrm{II})\right)$ is quantified. Then the magnetite layer oxidation rate, $k_{\text {mag }}$, and the FeCr spinel layer oxidation rate, $k_{\text {spinel }}$, can be evaluated. And the thickness $\left(h_{\mathrm{mag}}\right)$ of the magnetite layer and the thickness $\left(h_{\text {spinel }}\right)$ of $\mathrm{Fe}-\mathrm{Cr}$ spinel layer can be calculated also. The weight gain of oxide scale can be estimated by thickness of inner and outer layers of oxide scale with (7).

\section{Results and Discussion}

4.1. Iron Diffusion Coefficient in Magnetite and Fe-Cr Spinel Oxide. According to (4) and (5), the iron diffusion coefficient in magnetite and $\mathrm{Fe}-\mathrm{Cr}$ spinel oxide is evaluated at different temperatures. The relation between oxygen activity and iron diffusion coefficient in the oxides for HCM12A and NF616 is expressed as a function of logarithm of diffusion coefficients and logarithm of oxygen activity on Figure 2. The different kinds of diffusion regimes of iron diffusion coefficient in magnetite, vacancy, and interstitial are also specified on Figure 2.

The oxide growth kinetics depend on the oxygen activity in the interfaces. The self-iron diffusion has a strong dependence on the oxygen activity in the oxide. The value of the oxygen activity fixes the iron diffusion mechanism, which can follow either a vacancy mechanism for high-oxygen activities or an interstitial mechanism for low-oxygen activities.

In fact, the oxygen activity is low and the iron diffuses through the interstitial mechanism at the steel/oxide interface. The iron diffusion coefficient jumps from the $\mathrm{Fe}-\mathrm{Cr}$ spinel to the magnetite one at the $\mathrm{Fe}-\mathrm{Cr}$ spinel/magnetite interface. The diffusion mechanism at this site is still not predictable because the oxygen activity is needed to be calculated. The oxygen activity is high and the iron diffuses through the vacancy mechanism at the magnetite/supercritical interface.

4.2. Comparison between Simulation and Experiments of Oxide Weight Gain and Error Analysis. Using (1)-(5), (8), the simulation is performed for HAM12A and NF616 exposed to 


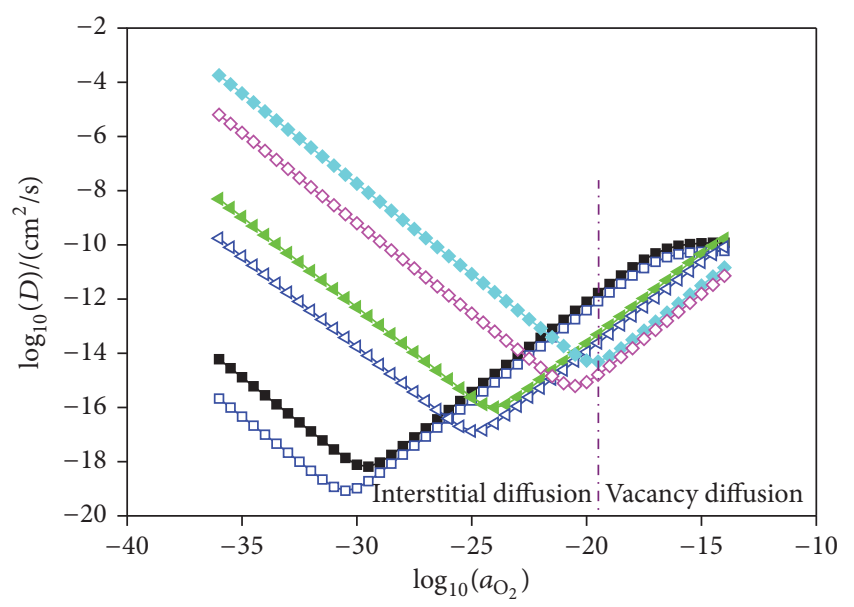

$\rightarrow-$ Iron diffusion coefficient in $\mathrm{Fe}_{3} \mathrm{O}_{4}$ at $400^{\circ} \mathrm{C}$

$\rightarrow-$ Iron diffusion coefficient in $\mathrm{Fe}_{2} \mathrm{CrO}_{4}$ at $400^{\circ} \mathrm{C}$

$\leftarrow$ Iron diffusion coefficient in $\mathrm{Fe}_{3} \mathrm{O}_{4}$ at $500^{\circ} \mathrm{C}$

$\triangleleft$ Iron diffusion coefficient in $\mathrm{Fe}_{2} \mathrm{CrO}_{4}$ at $500^{\circ} \mathrm{C}$

$\rightarrow$ Iron diffusion coefficient in $\mathrm{Fe}_{3} \mathrm{O}_{4}$ at $600^{\circ} \mathrm{C}$

$\checkmark$ Iron diffusion coefficient in $\mathrm{Fe}_{2} \mathrm{CrO}_{4}$ at $600^{\circ} \mathrm{C}$

(a)

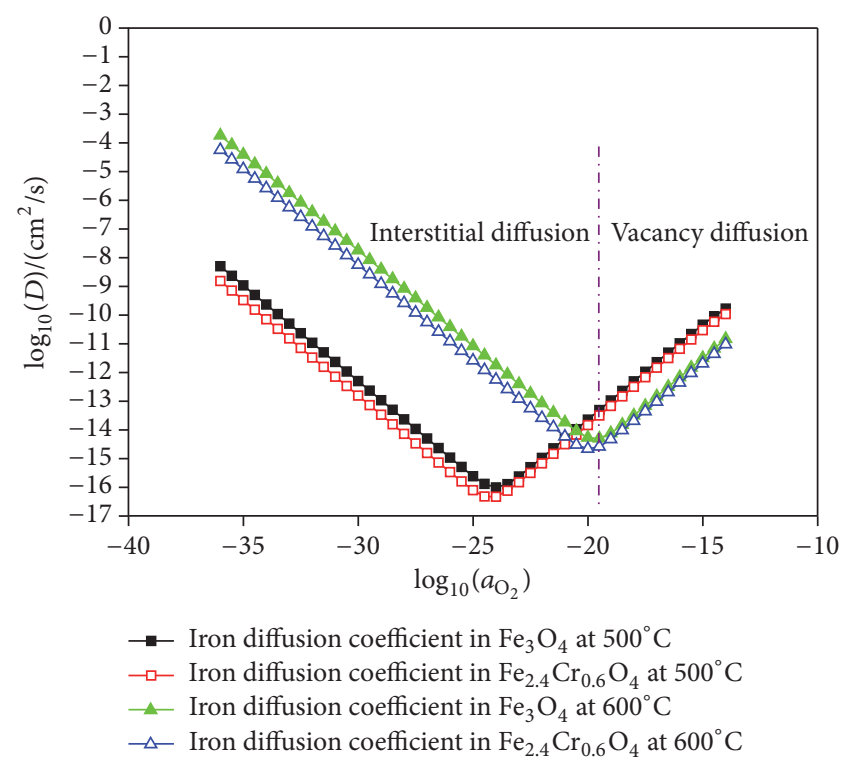

(b)

FIGURE 2: Iron diffusion coefficient of the duplex scale formed on HCM12A (a) and NF616 (b) as a function of oxygen activity in supercritical water at different temperatures.

supercritical water at $400^{\circ} \mathrm{C}, 500^{\circ} \mathrm{C}$, and $600^{\circ} \mathrm{C}$ under $25 \mathrm{MPa}$. The comparison between simulation and experiments of oxide weight gain are presented in Figure 3.

In [14], tests are performed on NF616 exposed to a SCW at 400,500 , and $600^{\circ} \mathrm{C}$ and $25 \mathrm{MPa}$ with an oxygen concentration of less than $25 \mathrm{ppb}$ in weight for time periods from 1 to $3000 \mathrm{~h}$.

For HCM12A, the simulation of oxidation weight gain is lower than experimental value at $500^{\circ} \mathrm{C}$ and $600^{\circ} \mathrm{C}$. The maximum difference between calculation and experiment of weight gain at $600^{\circ} \mathrm{C}$ is $104 \mathrm{mg} / \mathrm{dm}^{2}$ and is equivalent to thickness of about $7.5 \mu \mathrm{m}$ according to formula (8). The maximum difference between calculation and experiment of weight gain at $500^{\circ} \mathrm{C}$ is $181 \mathrm{mg} / \mathrm{dm}^{2}$ and is equivalent to thickness of about $13 \mu \mathrm{m}$. The maximum difference between calculation and experiment of weight gain at $400^{\circ} \mathrm{C}$ is $2 \mathrm{mg} / \mathrm{dm}^{2}$ and is equivalent to thickness of about $1.57 \mu \mathrm{m}$.

For NF616, the simulation of oxidation weight gain is higher than the experimental values at $600^{\circ} \mathrm{C}$. The maximum difference between calculation and experiment of weight gain at $600^{\circ} \mathrm{C}$ for 3000 hours is $306 \mathrm{mg} / \mathrm{dm}^{2}$ and is equivalent to thickness of about $22 \mu \mathrm{m}$. The reason is that the hematite phase was not detected in outer oxide layer [8], and the selective thermodynamic equilibrium oxygen partial pressure of reaction (6) is larger than actual pressure during calculation. The simulation of oxidation weight gain is lower than the experimental values at $500^{\circ} \mathrm{C}$. The maximum difference between calculation and experiment of weight gain for 3000 -hour exposure is $76 \mathrm{mg} / \mathrm{dm}^{2}$ and is equivalent to thickness of about $5.4 \mu \mathrm{m}$.
For 3000 hours of exposure, relative error of simulated weight gain by oxidation of HCM12A and NF616 in supercritical water at different temperatures compared to the experiments is shown in Figure 4.

The relative error of oxide weight gain between simulation and experiments on NF616 at $500^{\circ} \mathrm{C}$ and $600^{\circ} \mathrm{C}$ and HCM12A at $600^{\circ} \mathrm{C}$ is less than $20 \%$, and the calculated values are close to experimental values. The relative error of oxide weight gain between simulation and experiments on $\mathrm{HCM} 12 \mathrm{~A}$ at $400^{\circ} \mathrm{C}$ and $500^{\circ} \mathrm{C}$ is above $40 \%$.

4.3. Comparison and Analysis of Oxidation Rates. In [24], the temperature dependence of the parabolic rate constant is given by

$$
k_{\mathrm{EPRI}}=2 \cdot A \cdot \exp \left(-\frac{Q}{R T}\right)
$$

where $Q$ is the activation energy for the rate-controlling process, $T$ is the metal temperature (absolute), $A$ is the Arrhenius constant, and $R$ is the Universal Gas Constant. The oxidation parameters used for alloy NF616 are $Q=5.13 \times$ $10^{10} \mu \mathrm{m}^{2} / \mathrm{hr}$ and $A=169 \mathrm{~kJ} / \mathrm{mole}$. The oxidation parameters used for alloy HCM12A are $Q=5.6 \times 10^{4} \mu \mathrm{m}^{2} / \mathrm{hr}$ and $A=$ $75 \mathrm{~kJ} / \mathrm{mole}$.

According to the above equations, the oxidation rate of inner layer and outer layer and the global oxidation rate which is compared to the data in [24] are evaluated. These values are presented in Table 3 . 


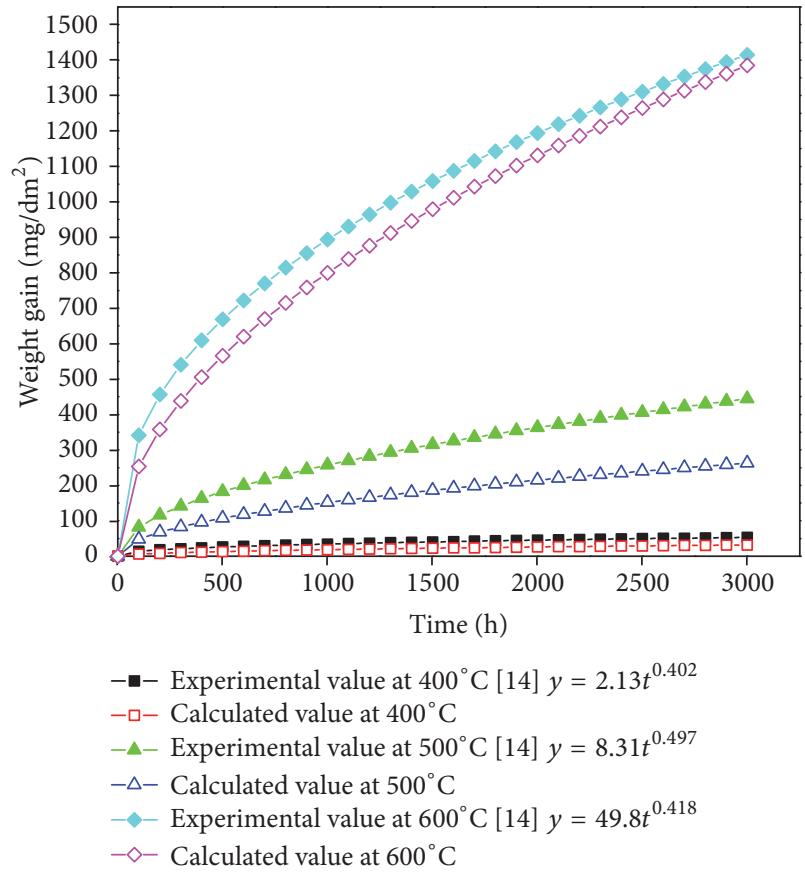

(a)

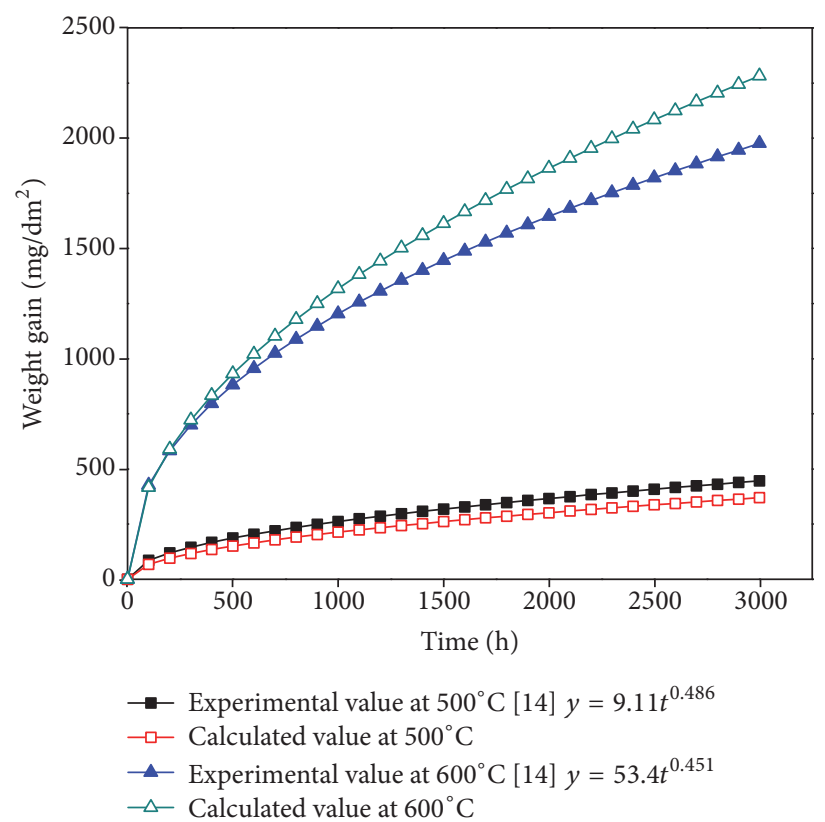

(b)

FiguRE 3: Experimental weight gain by oxidation of HCM12A (a) and NF616 (b) in supercritical water at different temperatures compared to the simulation.

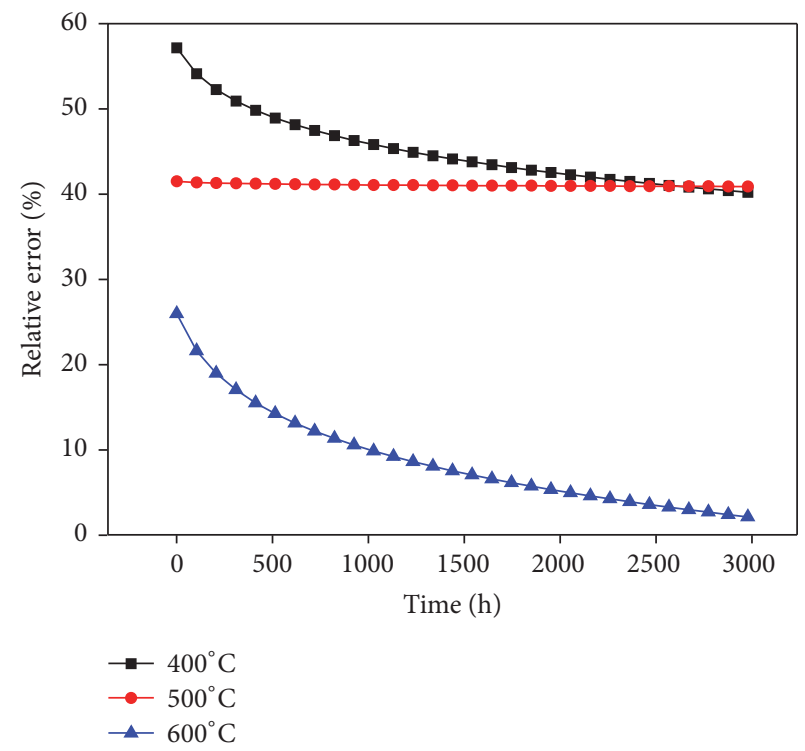

(a)

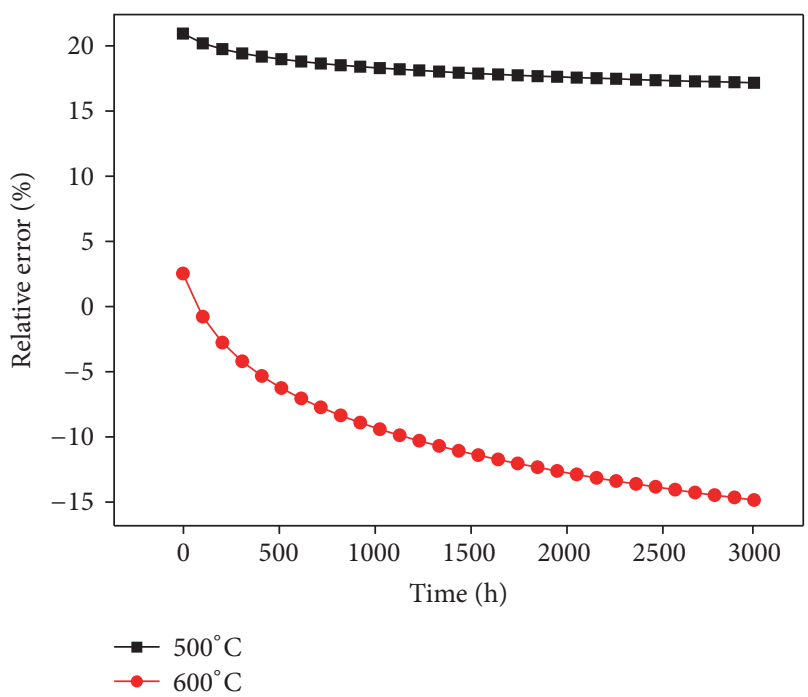

(b)

FIGURE 4: Relative error of simulated weight gain by oxidation of HCM12A (a) and NF616 (b) in supercritical water at different temperatures compared to the experiments.

The simulation of oxidation rates for NF616 and HCM12A at $550^{\circ} \mathrm{C}$ and $600^{\circ} \mathrm{C}$ are the same order of magnitude as one of the data in [24].

The simulation of oxidation rate for NF616 at $600^{\circ} \mathrm{C}$ is nearly two orders of magnitude higher than that at $500^{\circ} \mathrm{C}$, while the simulation of oxidation rate for $\mathrm{HCM} 12 \mathrm{~A}$ at $600^{\circ} \mathrm{C}$ is nearly one order of magnitude higher than that at $500^{\circ} \mathrm{C}$. The oxidation rate of $\mathrm{Fe}$-Cr spinel layer is lower than that of magnetite layer because of the presence of $\mathrm{Cr}$ in $\mathrm{Fe}-\mathrm{Cr}$ spinel layer. HCM12A with higher Cr contents show superior oxidation resistance as compared to NF616 with lower Cr contents at the same temperature. 
TABLE 3: Oxidation rate of inner and outer layer oxides, $k_{\text {mag }}$ and $k_{\text {spinel }}$, the global oxidation rate, $k_{\text {oxide }}$, and oxygen partial pressure of interfaces.

\begin{tabular}{|c|c|c|c|c|c|c|c|c|}
\hline \multirow{2}{*}{ Steel } & \multirow{2}{*}{ Temperature $\left({ }^{\circ} \mathrm{C}\right)$} & \multicolumn{4}{|c|}{ oxidation rate $\left(\mathrm{cm}^{2} / \mathrm{s}\right)$} & \multicolumn{3}{|c|}{ Oxygen partial pressure at interfaces (atm) } \\
\hline & & $k_{\mathrm{mag}}$ & $k_{\text {spinel }}$ & $k_{\text {oxide }}$ & $k_{\mathrm{EPRI}}[24]$ & $p_{\text {alloy/spinel }}$ & $p_{\text {spinel } / \mathrm{mag}}$ & $p_{\mathrm{mag} / \mathrm{scw}}$ \\
\hline \multirow{3}{*}{ NF616 } & 500 & $1.66 \times 10^{-13}$ & $1.61 \times 10^{-13}$ & $6.54 \times 10^{-13}$ & - & $1 \times 10^{-29}$ & $3.3 \times 10^{-21}$ & $3.5 \times 10^{-20}$ \\
\hline & 550 & $8.84 \times 10^{-13}$ & $8.57 \times 10^{-13}$ & $3.45 \times 10^{-11}$ & $5.35 \times 10^{-12}$ & $3.5 \times 10^{-27}$ & $3.97 \times 10^{-19}$ & $3.9 \times 10^{-18}$ \\
\hline & 600 & $6.33 \times 10^{-12}$ & $6.15 \times 10^{-12}$ & $2.5 \times 10^{-11}$ & $2.22 \times 10^{-11}$ & $2 \times 10^{-25}$ & $1.41 \times 10^{-23}$ & $2.57 \times 10^{-16}$ \\
\hline \multirow{4}{*}{ HCM12A } & 400 & $1.3 \times 10^{-15}$ & $1.13 \times 10^{-15}$ & $4.85 \times 10^{-15}$ & - & $3 \times 10^{-35}$ & $1.66 \times 10^{-25}$ & $3.46 \times 10^{-25}$ \\
\hline & 500 & $8.85 \times 10^{-14}$ & $7.7 \times 10^{-14}$ & $3.3 \times 10^{-13}$ & - & $1 \times 10^{-29}$ & $1.53 \times 10^{-20}$ & $3.5 \times 10^{-20}$ \\
\hline & 550 & $4.8 \times 10^{-13}$ & $4.17 \times 10^{-13}$ & $1.8 \times 10^{-12}$ & $5.4 \times 10^{-12}$ & $3.5 \times 10^{-27}$ & $1.7 \times 10^{-18}$ & $3.9 \times 10^{-18}$ \\
\hline & 600 & $2.46 \times 10^{-12}$ & $2.14 \times 10^{-12}$ & $9.2 \times 10^{-12}$ & $10.1 \times 10^{-12}$ & $2 \times 10^{-25}$ & $9.59 \times 10^{-17}$ & $2.57 \times 10^{-16}$ \\
\hline
\end{tabular}

4.4. The Distribution of Oxygen Activities and Iron Diffusion Coefficient in Duplex Oxide Scale. The oxygen partial pressures at interfaces of oxidation of HCM12A and NF616 at different temperatures are listed in Table 4. For the oxidation of $\mathrm{NF} 616$ at $600^{\circ} \mathrm{C}$, the oxygen activity in the Fe-Cr spinel layer evolves from $2 \times 10^{-25}$ to $1.41 \times 10^{-23}$, and the diffusion process follows an interstitial mechanism; the oxygen activity in the magnetite layer evolves from $1.41 \times 10^{-23}$ to $2.57 \times 10^{-16}$, and the diffusion process varies from a interstitial mechanism to a vacancy mechanism. For the oxidation of HCM12A at $600^{\circ} \mathrm{C}$, the oxygen activity in the $\mathrm{Fe}-\mathrm{Cr}$ spinel layer evolves from $2 \times 10^{-25}$ to $9.59 \times 10^{-17}$, and the diffusion process varies from a interstitial mechanism to a vacancy mechanism; the oxygen activity in the magnetite layer evolves from $9.59 \times$ $10^{-17}$ to $2.57 \times 10^{-16}$, and the diffusion process follows a vacancy mechanism.

The iron diffusion coefficient in the duplex scale of two ferritic-martensitic steels exposed to supercritical water for $3000 \mathrm{~h}$ is expressed as a function of normalized position $(x / X)$. Figure 5 shows calculations of the oxygen activity distribution in the $\mathrm{Fe}-\mathrm{Cr}$ spinel layer and the magnetite scale formed on NF616 and HCM12A at $600^{\circ} \mathrm{C}$ and $500^{\circ} \mathrm{C}$. Figure 6 shows the iron diffusion coefficient distribution along thickness direction of the duplex scale formed on NF616 and $\mathrm{HCM} 12 \mathrm{~A}$ at $600^{\circ} \mathrm{C}$ and $500^{\circ} \mathrm{C}$. In the duplex scale of two ferritic-martensitic steels, the oxygen activity is continuous, while the iron diffusion coefficient is discontinuous at the inner layer/outer layer interface.

For the oxidation of NF616 at $600^{\circ} \mathrm{C}$, the oxygen activity drastically increases at the normalized position $(x / X=$ $0.6)$, while iron diffusion coefficient becomes minimum. For the oxidation of $\mathrm{HCM} 12 \mathrm{~A}$ at $600^{\circ} \mathrm{C}$, the oxygen activity drastically increases at the normalized position $(x / X=0.2)$, while iron diffusion coefficient becomes minimum. There are two diffusion mechanisms of iron in the oxide, including interstitial mechanism and vacancy mechanism. When the vacancy concentration in oxide is high enough, the vacancies may collapse into voids. From Figure 2, with increasing of the oxygen activity, the diffusion mechanism changes from interstitial to vacancy. The vacancy diffusion mode starts to act a primary role at the location of the minimum diffusion coefficient of iron. So void is expected to form at the location of the minimum iron diffusion coefficient.
As shown in Figure 6, the iron diffusion coefficient in the Fe-Cr spinel layer on NF616 is higher than that in the $\mathrm{Fe}-\mathrm{Cr}$ spinel layer on HCM12A, while the iron diffusion coefficient in the magnetite layer on NF616 is close to that in the magnetite layer on HCM12A. The oxygen partial pressure at the inner layer/outer layer interface formed on NF616 and $\mathrm{HCM} 12 \mathrm{~A}$ at $500^{\circ} \mathrm{C}$ is $3.3 \times 10^{-21}$ and $1.53 \times 10^{-20}$, respectively (Table 4 ). The normalized position of the minimum iron diffusion coefficient in the duplex scale is about 0.4 and 0.1 (Figure 6), so the location of void formation in duplex scale formed on NF616 is close to the inner layer/outer layer interface compared to that formed on HCM12A. Similar result, which is that the minimum iron diffusion coefficient of low-oxygen exposed sample occurs at the location closer to the surface compared to high-oxygen exposed sample, has been reported in HCM12A oxidized in supercritical water [25].

4.5. Model Validation of an Example of One Power Plant. In the previous section, the model of oxidation kinetics of the ferritic-martensitic steel is validated with experimental data of Tan et al. [14]. In this section, the tubes (T91 steel) of the final superheater in one power plant are selected as research objects, and the thickness of steam side oxide scales of the final superheater is estimated by the above method. The simulation results are compared with field measurement data of the oxide scale thickness and calculation results by the EPRI's oxidation kinetics parameters.

Since its service, exfoliation of the oxide scale has become an acute problem in a $600 \mathrm{MW}$ supercritical unit of one power plant, whose boiler type is SG2080/25.4-M969. The main thermodynamic parameters of the boiler, for example, calculation, are listed in Table 4 . The thicknesses of oxide scales of the outlet part of the final superheater are measured by ultrasonic technology after $13000 \mathrm{~h}, 21000 \mathrm{~h}, 25000 \mathrm{~h}$, and $36000 \mathrm{~h}$ periods of service. The range of values of thickness of oxide scales is listed in Table 5.

In order to verify the simulation of oxidation kinetics of ferritic-martensitic steels, an oxide scale growth model of superheater tubes is established. The empirical formula correlating scale thickness with the simulation oxidation rates is combined to the heat transfer theory. The model involves forced convections on the inner surface due to the 
TABLE 4: Main thermodynamic parameters of a boiler, for example, calculation.

\begin{tabular}{lccc}
\hline Item & Unit & BRL & BMCR \\
\hline Superheated steam mass flow & $\mathrm{t} / \mathrm{h}$ & 1979 & 2080 \\
Pressure of superheated steam outlet & $\mathrm{MPa}$ & 25.28 & 571 \\
Temperature of superheated steam outlet & ${ }^{\circ} \mathrm{C}$ & 1638 & 571 \\
Reheated steam flow & $\mathrm{t} / \mathrm{h}$ & 4.38 & 1764 \\
Pressure of reheated steam inlet & $\mathrm{MPa}$ & 3.28 & 4.6 \\
Pressure of reheated steam outlet & $\mathrm{MPa}$ & 313 & 3.66 \\
Temperature of reheated steam inlet & ${ }^{\circ} \mathrm{C}$ & 569 & 318 \\
Temperature of reheated steam outlet & ${ }^{\circ} \mathrm{C}$ & 569 \\
\hline
\end{tabular}

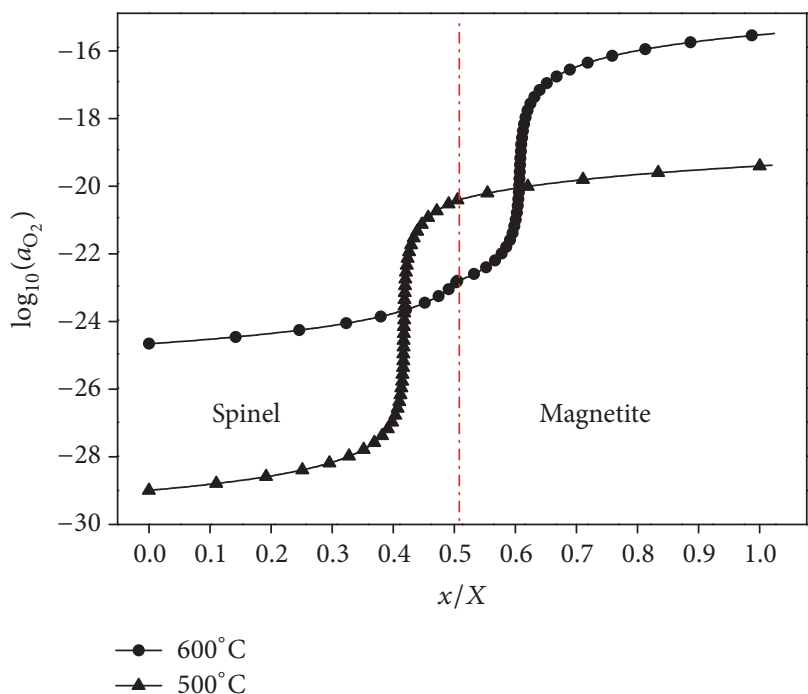

(a)

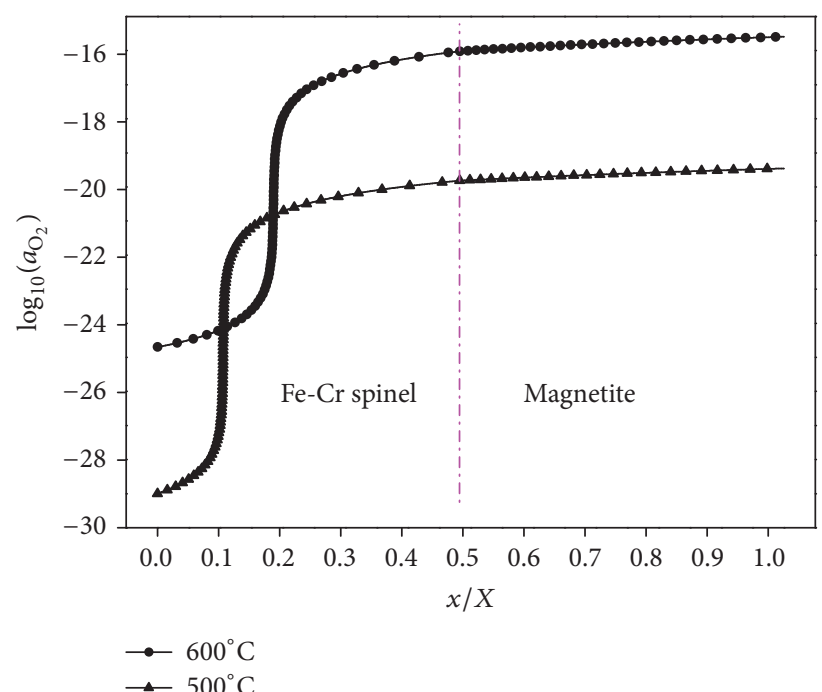

(b)

FIgURE 5: The calculation oxygen activity in the duplex scale formed on NF616 (a) and HCM12A (b) as a function of normalized position.

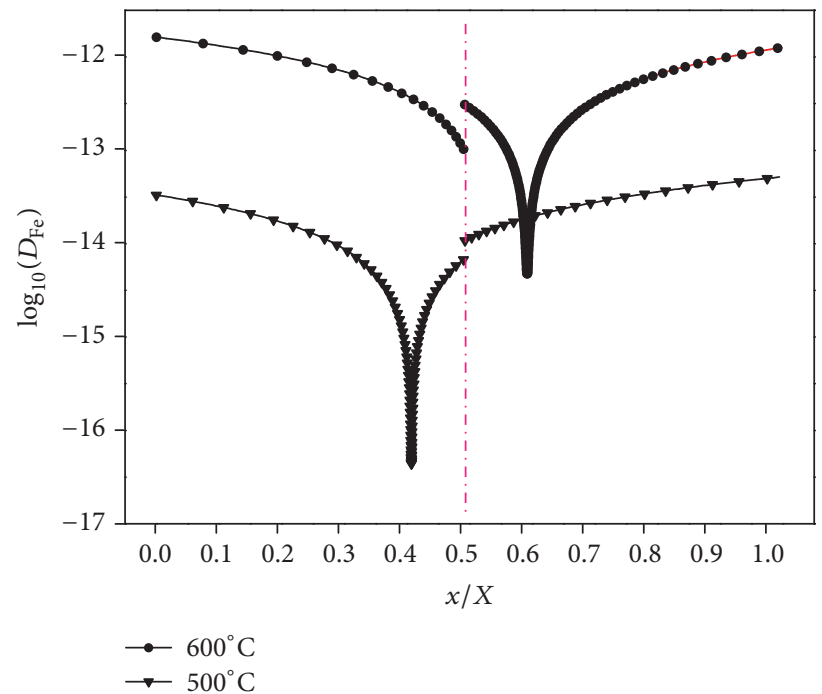

(a)

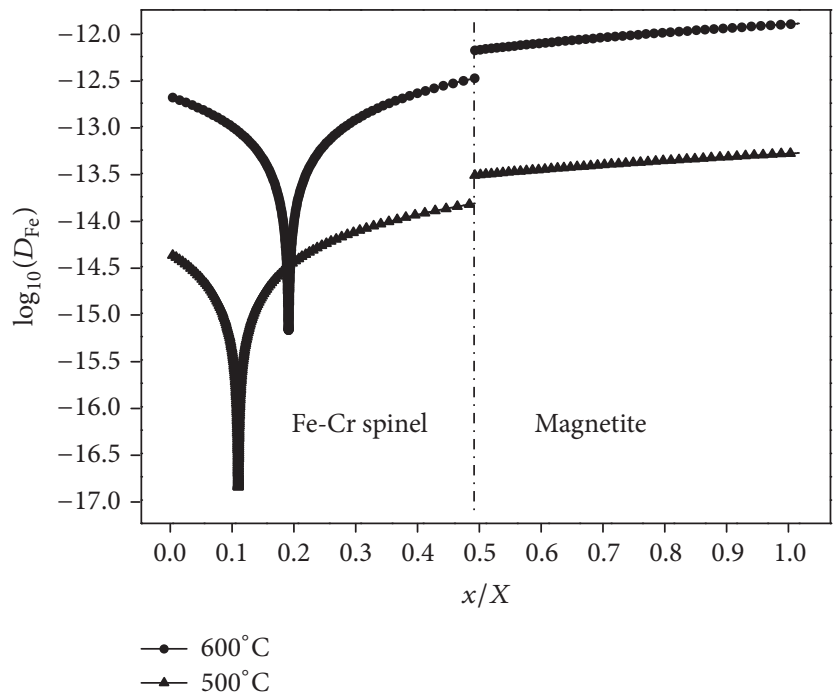

(b)

Figure 6: The diffusion coefficient of iron in the duplex scale formed on NF616 (a) and HCM12A (b) as a function of the normalized position. 
TABLE 5: Comparison between field measurement data and simulation results of oxide scale thickness.

\begin{tabular}{lccc}
\hline $\begin{array}{l}\text { Exposure } \\
\text { time/h }\end{array}$ & $\begin{array}{c}\text { Field } \\
\text { measurement } \\
\text { data of oxide } \\
\text { scale } \\
\text { thickness/ } \mu \mathrm{m}\end{array}$ & $\begin{array}{c}\text { Simulation } \\
\text { results of } \\
\text { oxide scale } \\
\text { thickness/ } \mu \mathrm{m}\end{array}$ & $\begin{array}{c}\text { Relative error } \\
\text { compared to } \\
\text { the } \\
\text { maximum } \\
\text { value/\% }\end{array}$ \\
\hline 10000 & $116-148$ & 177.5 & 19.9 \\
21000 & $188-209$ & 225.6 & 7.9 \\
25000 & $187-225$ & 246.1 & 9.4 \\
36000 & $144-258$ & 295.4 & 14.5 \\
\hline
\end{tabular}

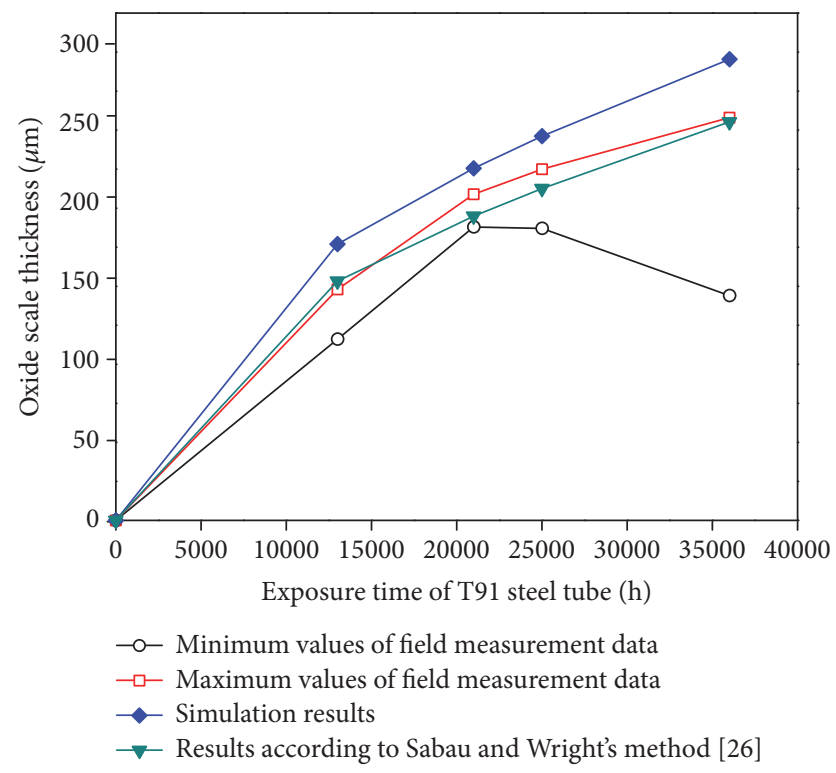

FIGURE 7: Comparison of the thickness of oxide scale of final superheater tubes during the oxidation of T91 for different exposure time among field measurement data, simulation results, and calculation results according to Sabau and Wright's method [26].

turbulent flow of steam and on the outer surface due to cross flow of the hot flue gas over ash tubes. The oxidation rates of ferritic-martensitic steels at different temperatures are calculated and carried out by a quadratic multinomial fitting. An iterative procedure is used to determine scale thickness as both temperature and time increase [26]. The results are presented in Figure 7.

Based on the parabolic law of high-temperature oxidation, Arrhenius equation, and related basic theories of heat transfer, an oxide scale growth model of boiler superheater tubes is proposed through iterative technique [26]. Related parameters are from the EPRI report [24]. According to this algorithm, the calculation results of oxide scale thickness of boiler superheater tubes for different exposure time are presented in Figure 7.

Figure 7 shows the predicted oxide scale thickness, the field measurement data, and calculated results by Sabau and Wright's method. From this figure, it can be concluded that the prediction results are credible. The calculation results of

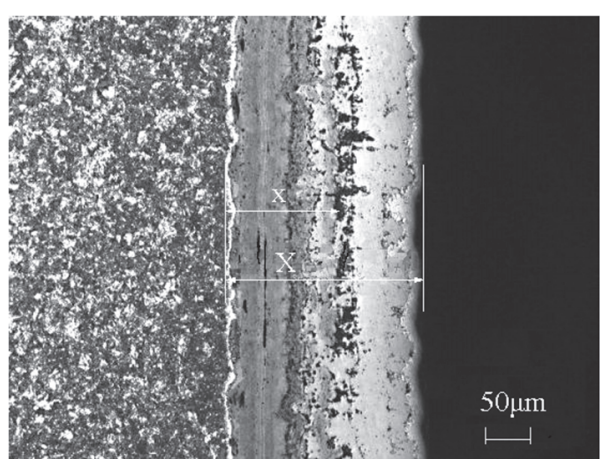

FIgURE 8: A cross-sectional SEM image of the oxide layer formed on T91 used in a superheater tube for 25000 hours.

this method and Sabau and Wright's method are comparatively close to field measurement data. Because exfoliation of oxide scales probably emerged during the operation of the unit, the maximum value of the field measurement data is lower than calculation results of oxide thickness of boiler superheater tubes. The parameters in Adrian's iterative method are extrapolated from field measurement data, so the calculated results are closer to the actual experimental data.

To verify the location of voids, the scanning electron microscope image of the oxide layer formed on T91 used in a superheater tube for 25000 hours is captured and shown in Figure 8. The experimental thickness of oxide scale is $225.34 \mu \mathrm{m}$, and the distance is $125.2 \mu \mathrm{m}$ from the steel/Fe$\mathrm{Cr}$ spinel interface to the location of void formation. The calculated quantitative location of voids formation $(x / X=$ $0.52)$ is in good agreement with the experimental result $(x / X=0.56)$ with minor difference.

\section{Conclusion}

Based on available space model, the oxidation kinetics of two ferritic-martensitic steels are developed to predict in supercritical water at $400^{\circ} \mathrm{C}, 500^{\circ} \mathrm{C}$, and $600^{\circ} \mathrm{C}$. The iron diffusion coefficients in magnetite and $\mathrm{Fe}-\mathrm{Cr}$ spinel, which are extrapolated from studies of Backhaus-Ricoult and Dieckmann [17] and Töpfer et al. [18], are used for calculation of oxidation kinetics of steels under supercritical water environment. The main conclusions are as follows.

(i) The simulation of oxidation of $\mathrm{NF} 616$ at $500^{\circ} \mathrm{C}$ and $600^{\circ} \mathrm{C}$ and $\mathrm{HCM} 12 \mathrm{~A}$ at $600^{\circ} \mathrm{C}$ is approximately close to the experimental weight gain during the oxidation of NF616 and HCM12A in supercritical water at $400-600^{\circ} \mathrm{C}[14]$, which proves the validity of the simulation assumptions.

(ii) The simulation value of the oxidation rate depends on oxygen partial pressure at the steel/spinel interface and magnetite/supercritical water interface. The equilibrium oxygen partial pressure of reaction (6) is used as oxygen partial pressure at magnetite/supercritical water interface, and the results of calculation are in agreement with the experimental weight gain. 
(iii) The relative error of oxide weight gain between simulation and experiments of $\mathrm{HCM} 12 \mathrm{~A}$ at $400^{\circ} \mathrm{C}$ and $500^{\circ} \mathrm{C}$ is above $40 \%$, and the reason is that magnetite/supercritical water oxygen partial pressure is not the equilibrium oxygen partial pressure of reaction (6) or probably the error of diffusion coefficient when it extrapolated from high temperature to low temperature according to Töpfer et al's data [18].

(iv) In the duplex scale of two ferritic-martensitic steels, the oxygen activity is continuous, while the iron diffusion coefficient is discontinuous at the inner layer/outer layer interface. The oxygen activity drastically increases at one normalized position $(x / X)$, while iron diffusion coefficient becomes minimum. Void is expected to form at the location of the minimum iron diffusion coefficient.

(v) At the same oxidation temperature, the iron diffusion coefficient in the Fe-Cr spinel layer on NF616 is higher than that in the Fe-Cr spinel layer on HCM12A, while the iron diffusion coefficient in the magnetite layer on NF616 is close to that in the magnetite layer on HCM12A.

\section{Conflicts of Interest}

The authors declare that there are no conflicts of interest regarding the publication of this paper.

\section{Acknowledgments}

This paper was supported by the Fundamental Research Funds for the Central Universities (2014MS107).

\section{References}

[1] P. Kritzer, "Corrosion in high-temperature and supercritical water and aqueous solutions: a review," Journal of Supercritical Fluids, vol. 29, no. 1-2, pp. 1-29, 2004.

[2] R. L. Klueh and A. T. Nelson, "Ferritic/martensitic steels for next-generation reactors," Journal of Nuclear Materials, vol. 371, no. 1-3, pp. 37-52, 2007.

[3] S. R. J. Saunders, M. Monteiro, and F. Rizzo, "The oxidation behaviour of metals and alloys at high temperatures in atmospheres containing water vapour: a review," Progress in Materials Science, vol. 53, no. 5, pp. 775-837, 2008.

[4] W. J. Quadakkers, J. Zurek, and M. Hänsel, "Effect of water vapor on high-temperature oxidation of FeCr alloys," JOM Journal of the Minerals Metals and Materials Society, vol. 61, no. 7, pp. 44-50, 2009.

[5] P. Ampornrat and G. S. Was, "Oxidation of ferritic-martensitic alloys T91, HCM12A and HT-9 in supercritical water," Journal of Nuclear Materials, vol. 371, no. 1-3, pp. 1-17, 2007.

[6] I. Betova, M. Bojinov, P. Kinnunen et al., "Composition, structure, and properties of corrosion layers on ferritic and austenitic steels in ultrasupercritical water," Journal of the Electrochemical Society, vol. 153, no. 11, Article ID 020611JES, pp. B464-B473, 2006.

[7] M. G. Angell, S. K. Lister, and A. Rudge, "The effect of steam pressure on the oxidation behavior of annealed 9CrlMo boiler tubing materials," in Proceedings of the in 15th International Conference on the Properties of Water and Steam (ICPWS XV), pp. 1-9, Berlin, Germany, 2008.

[8] N.-Q. Zhang, H. Xu, B.-R. Li, Y. Bai, and D.-Y. Liu, "Influence of the dissolved oxygen content on corrosion of the ferriticmartensitic steel P92 in supercritical water," Corrosion Science, vol. 56, pp. 123-128, 2012.

[9] L. Tan, Y. Yang, and T. R. Allen, "Oxidation behavior of ironbased alloy HCM12A exposed in supercritical water," Corrosion Science, vol. 48, no. 10, pp. 3123-3138, 2006.

[10] J. Bischoff and A. T. Motta, "Oxidation behavior of ferriticmartensitic and ODS steels in supercritical water," Journal of Nuclear Materials, vol. 424, no. 1-3, pp. 261-276, 2012.

[11] X. Zhong, X. Wu, and E.-H. Han, "Effects of exposure temperature and time on corrosion behavior of a ferritic-martensitic steel P92 in aerated supercritical water," Corrosion Science, vol. 90, pp. 511-521, 2015.

[12] L. Martinelli, F. Balbaud-Célérier, G. Picard, and G. Santarini, "Oxidation mechanism of a Fe-9Cr-1Mo steel by liquid $\mathrm{Pb}-\mathrm{Bi}$ eutectic alloy (Part III)," Corrosion Science, vol. 50, no. 9, pp. 2549-2559, 2008.

[13] F. Rouillard and L. Martinelli, "Corrosion of 9Cr steel in $\mathrm{CO}_{2}$ at intermediate temperature III: Modelling and simulation of void-induced duplex oxide growth," Oxidation of Metals, vol. 77, no. 1-2, pp. 71-83, 2012.

[14] L. Tan, X. Ren, and T. R. Allen, "Corrosion behavior of 9-12\% $\mathrm{Cr}$ ferritic-martensitic steels in supercritical water," Corrosion Science, vol. 52, no. 4, pp. 1520-1528, 2010.

[15] L. Martinelli, F. Balbaud-Célérier, A. Terlain, S. Bosonnet, G. Picard, and G. Santarini, "Oxidation mechanism of an Fe-9Cr$1 \mathrm{Mo}$ steel by liquid $\mathrm{Pb}-\mathrm{Bi}$ eutectic alloy at $470^{\circ} \mathrm{C}$ (Part II)," Corrosion Science, vol. 50, no. 9, pp. 2537-2548, 2008.

[16] A. Atkinson, M. L. O’Dwyer, and R. I. Taylor, “55Fe diffusion in magnetite crystals at $500^{\circ} \mathrm{C}$ and its relevance to oxidation of iron," Journal of Materials Science, vol. 18, no. 8, pp. 2371-2379, 1983.

[17] M. Backhaus-Ricoult and R. Dieckmann, "Defects and cation diffusion in magnetite (VII): diffusion controlled formation of magnetite during reactions," Berichte der Bunsengesellschaft für physikalische Chemie, vol. 90, no. 8, pp. 690-698, 1986.

[18] J. Töpfer, S. Aggarwal, and R. Dieckmann, "Point defects and cation tracer diffusion in $\left(\mathrm{Cr}_{x} \mathrm{Fe}_{1-x}\right)_{3-\delta} \mathrm{O}_{4}$ spinels," Solid State Ionics, vol. 81, no. 3-4, pp. 251-266, 1995.

[19] P. Ampornrat, Determination of oxidation mechanisms of ferritic - martensitic steels in supercritical water, The University of Michigan, 2011.

[20] J. Zurek, M. Michalik, F. Schmitz, T.-U. Kern, L. Singheiser, and W. J. Quadakkers, "The effect of water-vapor content and gas flow rate on the oxidation mechanism of a $10 \% \mathrm{Cr}$-ferritic steel in $\mathrm{Ar}-\mathrm{H}_{2} \mathrm{O}$ mixtures," Oxidation of Metals, vol. 63, no. 5-6, pp. 401-422, 2005.

[21] T. Furukawa, G. Müller, G. Schumacher, A. Weisenburger, A. Heinzel, and K. Aoto, "Effect of oxygen concentration and temperature on compatibility of ODS steel with liquid, stagnant Pb45Bi55," Journal of Nuclear Materials, vol. 335, no. 2, pp. 189193, 2004.

[22] D. R. Gaskell, Introduction to Metallurgical Thermodynamics, Taylor, Francis, London, 2nd edition, 1981.

[23] T. Maruyama, N. Fukagai, M. Ueda, and K. Kawamura, "Chemical potential distribution and void formation in magnetite scale formed in oxidation of iron at 823K," Materials Science Forum, vol. 461-464, no. II, pp. 807-814, 2004. 
[24] I. G. Wright and P. F. Tortorelli, "Program on technology innovation: oxide growth and exfoliation on alloys exposed to steam," Tech. Rep., Electric Power Research Institute, PaloAlto, Calif, USA, 2007.

[25] L. Tan, Y. Yang, and T. R. Allen, "Porosity prediction in supercritical water exposed ferritic/martensitic steel HCM12A," Corrosion Science, vol. 48, no. 12, pp. 4234-4242, 2006.

[26] A. S. Sabau and I. G. Wright, "On the estimation of thermal strains developed during oxide growth," Journal of Applied Physics, vol. 106, no. 2, Article ID 023503, 8 pages, 2009. 

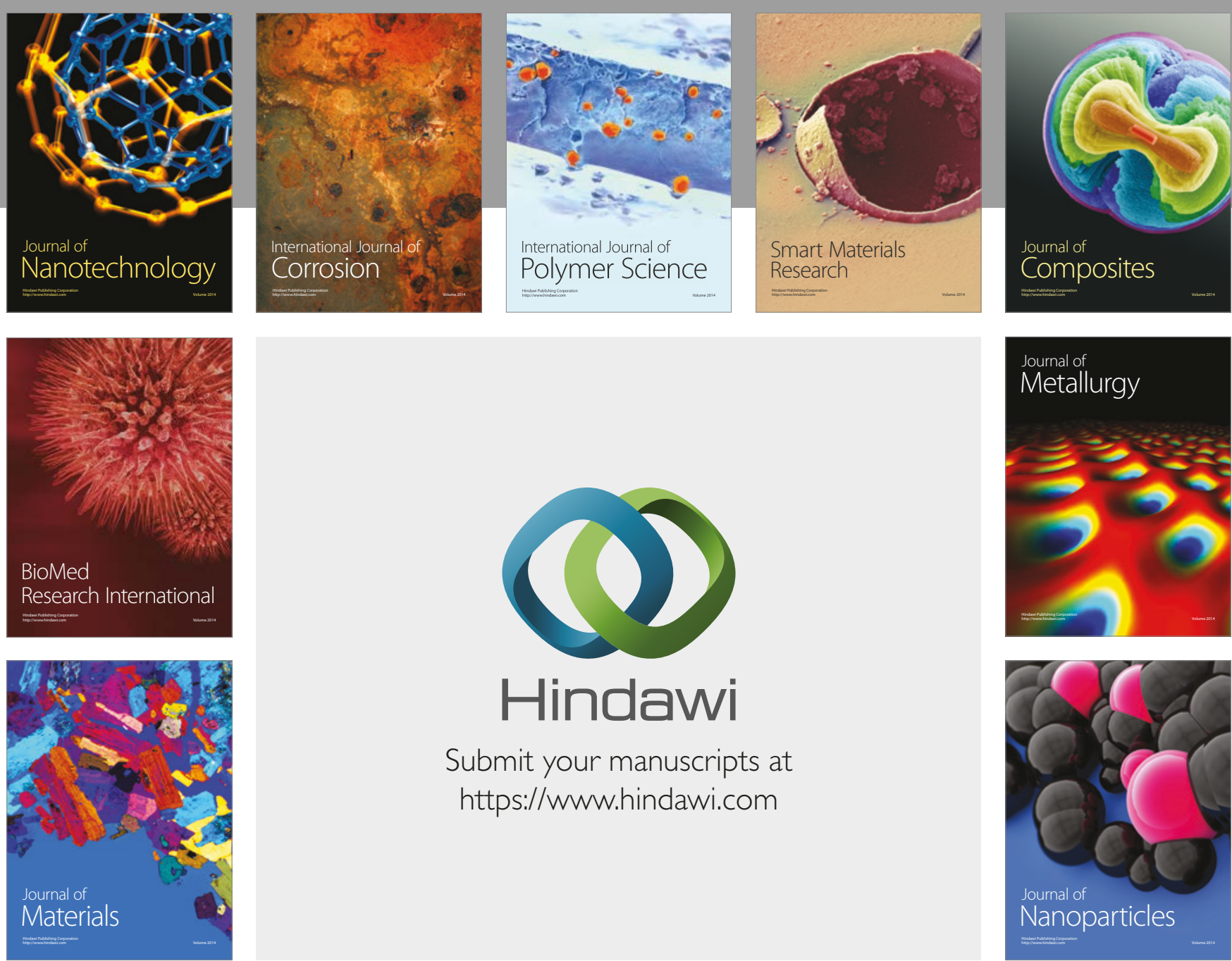

\section{Hindawi}

Submit your manuscripts at

https://www.hindawi.com
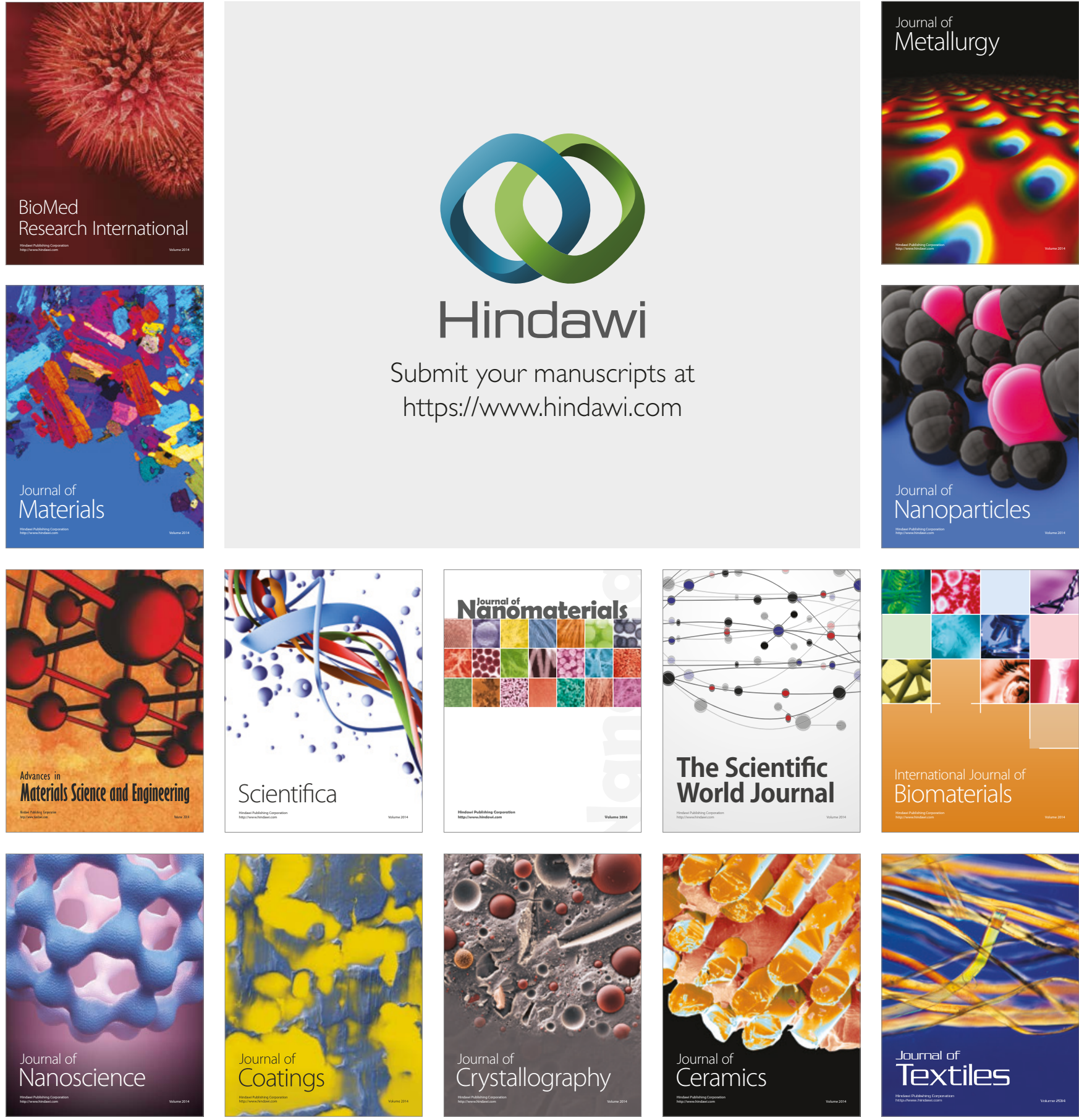

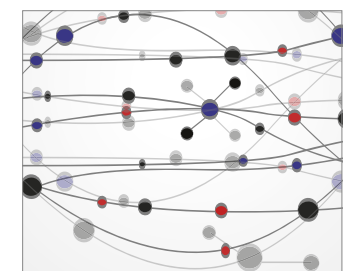

The Scientific World Journal
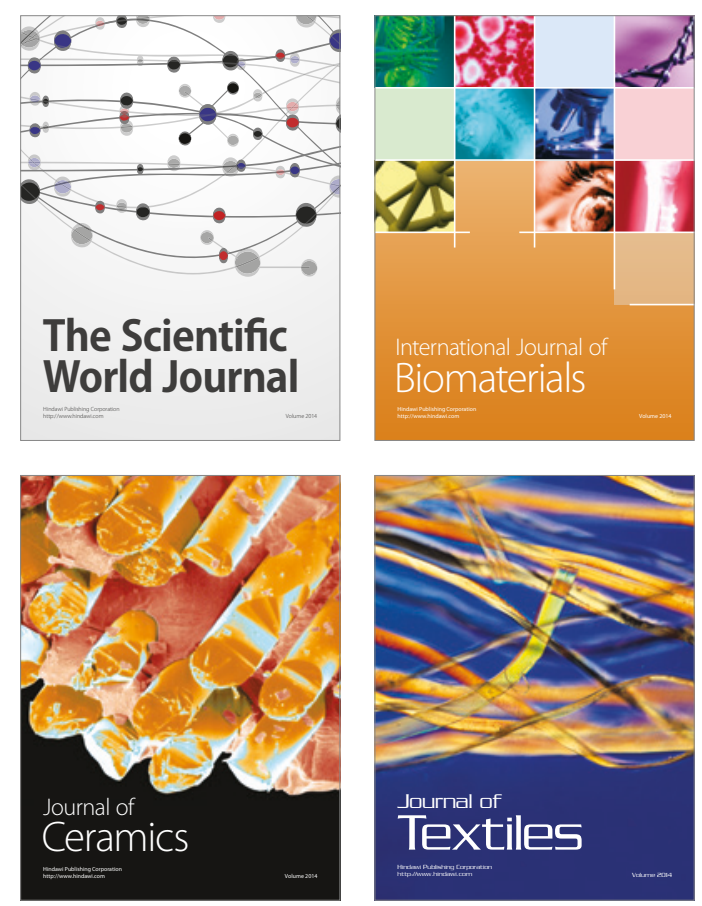